This item was submitted to Loughborough's Research Repository by the author.

Items in Figshare are protected by copyright, with all rights reserved, unless otherwise indicated.

\title{
Thermal effects on stereolithography tools during injection moulding
}

PLEASE CITE THE PUBLISHED VERSION

PUBLISHER

(C) Emerald Group Publishing Limited

LICENCE

CC BY-NC-ND 4.0

\section{REPOSITORY RECORD}

Ribeiro, Armando Sá, Neil Hopkinson, and Carlos Henrique Ahrens. 2019. "Thermal Effects on Stereolithography Tools During Injection Moulding”. figshare. https://hdl.handle.net/2134/3508. 
This item was submitted to Loughborough's Institutional Repository by the author and is made available under the following Creative Commons Licence conditions.

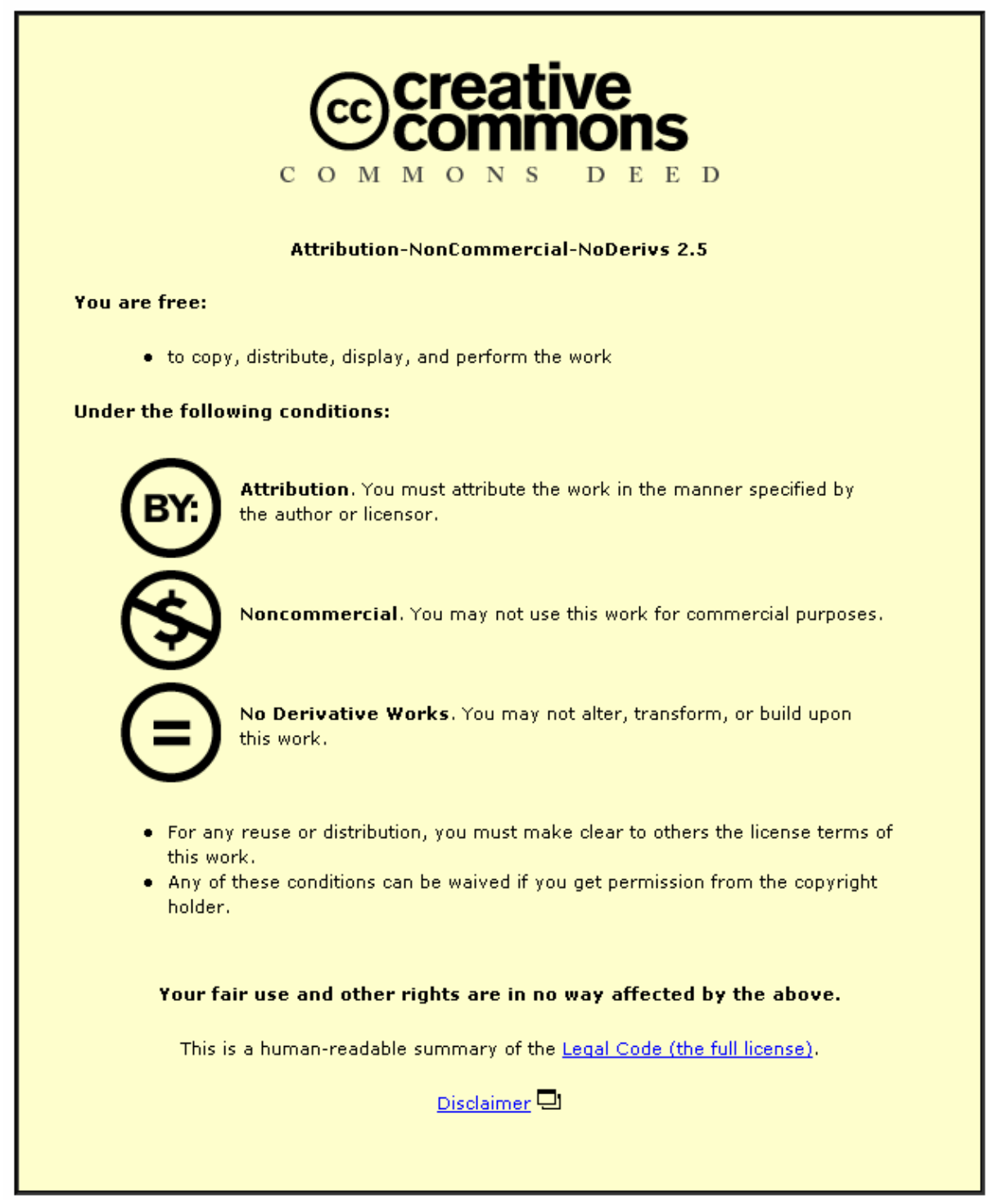

For the full text of this licence, please go to: http://creativecommons.org/licenses/by-nc-nd/2.5/ 


\title{
Thermal Effects on Stereolithography Tools during Injection Moulding
}

\section{Keywords}

Stereolithography Tooling, Injection Moulding, Direct AIM, Thermal Effects on Stereolithography Resin

\begin{abstract}
In this work the changes to stereolithography (SL) resin mechanical properties during the injection moulding process were evaluated. A multi-impression SL mould was built and used to inject a series of small flat mouldings. The fixed half SL tool insert included recesses to accommodate tensile test specimens. Tensile test specimens made from SL resin were positioned in these recesses and plastic parts were injected. After injecting a predetermined number of mouldings, tensile tests were performed using the tensile test specimens. The results from the tensile tests showed that the thermal cycling encountered during the injection moulding process did not significantly affect the mechanical properties of the resin. Observations indicated that reducing the temperatures encountered in the tool may lead to longer tool life.
\end{abstract}

\section{Introduction}

Stereolithography parts are widely used as masters for vacuum casting and other prototyping applications (Wohlers, 2001). Since the mid 1990's there has been some use of SL parts as injection moulding tools - a process known as Direct $\mathrm{AIM}^{\mathrm{TM}}$. Initially the use of SL tools was promoted as a fast means of creating injection moulded parts from a CAD file in the desired production material (Jacobs, 1997). More recently there has been interest in using the low conductivity of SL tools along with the ability of SL to create parts directly with deep slots to produce fine, thin walled components (Connelly \& Parunak, 2002). 
The use of SL moulds to obtain short runs of plastic injected parts has been limited, mainly due to premature mould failure and a consequent lack of confidence in the process. Previous research has shown that catastrophic mould failure occurs during injection (Rahmati \& Dickens, 1997) and ejection (Jacobs, 1997; Cedorge et al., 1999). Incremental mould failure such as chipping away of small parts of the tool surface has also been documented (Jacobs, 1997). All of these modes of failure are due to some extent to the mechanical properties of the resin.

Much of the reported work on SL tools shows that failure occurs after a number of shots have been moulded, however experimental results indicate that loads on the tool such as bending and shear during injection and tensile forces applied to core features during ejection do not increase from one shot to the next (Hopkinson et al., 1999; Cedorge et al, 1999). Therefore it is suggested that failure occurs due to changes in mechanical properties of the resin over time or due to a reduction in the Ultimate Tensile Stress (UTS) when the tool temperature is increased.

Previous work has suggested that the elevated temperatures encountered during injection moulding will cause continued curing of the tool and decreases in the ejection forces required (Colton \& Blair, 1999). Other work has shown that tools built in some SL resins that have been subjected to thermal post curing, have been too brittle for use in injection moulding. Experiments performed using SL7110 resin showed that thermal post curing increase the UTS and Young's Modulus (Salmoria et al, 2002). Conversely, McLaughlin Jr. (1996) reported that post curing SL5170 did not significantly change these properties.

A clear understanding of SL resin behaviour when it is submitted to thermal cycling during the injection moulding process will help to identify when the process should be used or avoided; it should also help to highlight good practice such as reducing any detrimental thermal effects that may lead to premature tool failure. With such an understanding, simulation of the thermal load applied to a tool during the injection moulding process may help to predict premature failure. Ultimately results of Finite Element Analysis simulations could help to predict and minimise thermal deterioration of a tool. 


\section{Background - Curing Stereolithography Resin}

The materials used in the stereolithography process are generally epoxy-based photopolymers with additives that provide some desired properties for various applications. These materials are submitted to curing during and after the stereolithography process, as described below.

\section{Ultra-violet Curing}

The stereolithography process uses UV light to cure the resin, initiating cross-linking reactions to create a solid thermoset. During this process, free monomer radicals react chemically with photo-initiators, forming molecules called polymerisation-initiating species (Jacobs, 1992). These molecules react with others forming the final crosslinked polymer. Post curing in ultra-violet oven helps to cure any uncured resin on the part surface.

\section{Thermal Curing}

After building and UV post curing, some SL resins are subject to thermal curing resulting in a higher degree of cross-linking due the existence of free radicals (Colton \& Blair, 1999). This cross-linking occurs between molecules that did not have any contact with each other during the part building and post curing processes. High temperatures increase the free radicals' mobility, inducing further cross-linking between them. However, the degree of this additional cure depends on the resin and the build parameters used.

Effects of curing on mechanical properties of the resin

SL moulds are usually exposed to elevated temperature during the injection moulding process. This procedure may promote additional curing in SL resin, increasing the cross-linking, which can significantly change the properties of the material, such as the glass transition temperature and ductility. Jacobs (1992) showed how the continued thermal polymerisation increases the flexural modulus of SL resin. Other mechanical properties of the material, such as Young's Modulus and UTS, could change significantly due to the thermal cure (Salmoria et al, 2002). 
The mechanical properties of a thermoset polymer depend on its cross-link density and the polymerisation process. Polymers with high cross-link density usually show high dimensional stability under loads, high mechanical strength and glass transition temperature. However, polymers with low cross-link density show a high degree of elasticity. Curing parameters such as temperature and time also affect the mechanical properties of SL resin.

A thermal aspect that could affect SL resin properties is how a thermal load has been applied. Previous work has evaluated the thermal cure of SL resin when it has been submitted to a constant temperature above the glass transition temperature (McLaughlin Jr., 1996). However, during the injection moulding process the material is submitted to a thermal cycle when it is heated and cooled successively. It is therefore of interest to evaluate the effect of cycle thermal loading encountered during the injection moulding process on mechanical properties of the resin.

\section{Methodology}

To determine the changes in the mechanical properties of SL resin that occur during the injection moulding process, it was necessary to submit the material to the same conditions observed in practical conditions (thermal cycles). After this thermal cycling, the variations of the mechanical properties were measured by tensile testing.

\section{Mould Design}

The first stage of the experiment was to design an injection mould that could be used to subject tensile test specimens to the thermal cycles. This mould is shown in the Figure 1. 


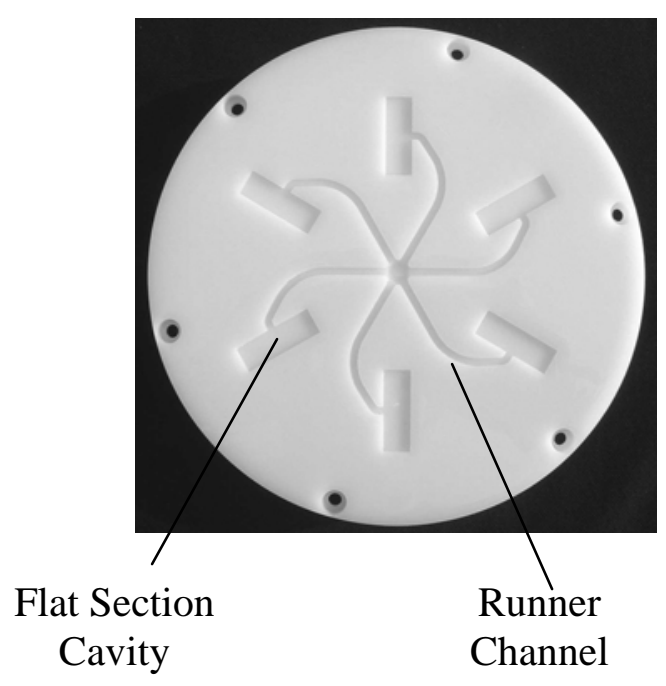

(a) MOVING MOULD

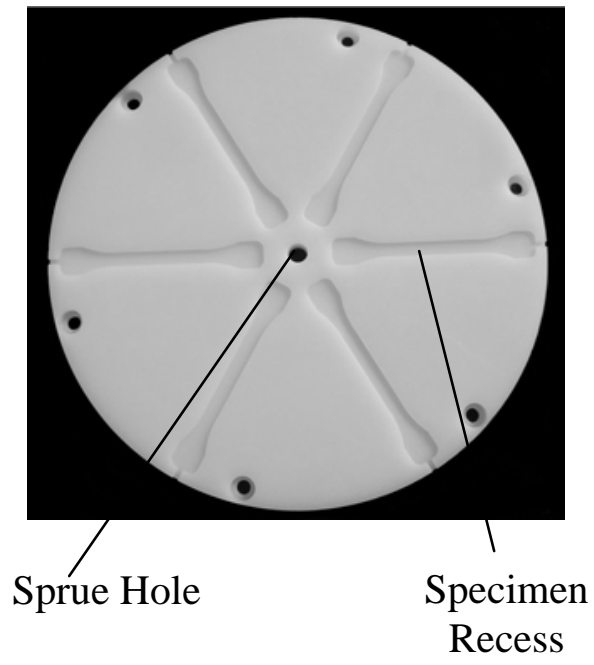

(b) FIXED MOULD

Figure 1 - SL injection mould

The multi-impression mould showed in Figure 1 has six recesses in the fixed half (b) where tensile specimens were positioned. The specimen's dimensions are in accordance with the BS EN ISO 527-2: 1996 for plastics determination of tensile properties. The injected parts consisted of six flat sections that measured 30x10x2mm. The six specimens were positioned to be in direct contact with the moulding material. A circular shaped axis-symmetric mould (164 mm diameter) was used to guarantee the same thermal conditions for all specimens evaluated.

A type $\mathrm{K}$ thermocouple was positioned in the moving half of the tool to monitor the temperature during the injection moulding process as showing in Figure 2. In order to keep the thermocouple in the designated position, Araldite ${ }^{\circledR}$ Epoxy glue was used to hold it in place to ensure a good thermal contact.

\section{Injection Moulding Process}

The mould showed in Figure 1 was built on 3D System SLA 7000 machine using Vantico SL7560 resin. A Battenfeld Injection Moulding Machine (TM 750/210) was used to inject parts with Solvay Polypropylene. The injection parameters used are shown in Table 1; these were based on parameters used in previous research (Hopkinson 1999). The mould temperature data were recorded every second using a Data Logger connected to a Pentium $133 \mathrm{MHz}$ computer. The thermocouple readings were used to control the cooling cycle. 


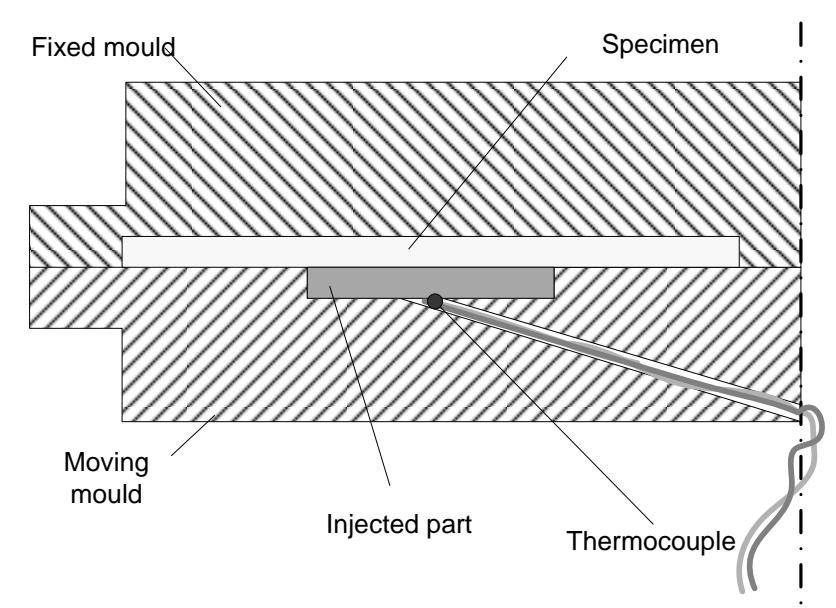

Figure 2 - Thermocouple channels

\begin{tabular}{|l|c|}
\hline \multicolumn{1}{|c|}{ Parameter } & Values \\
\hline Nozzle Temperature & $200{ }^{0} \mathrm{C}$ \\
\hline Injection Speed & $3 \mathrm{~mm} / \mathrm{s}$ \\
\hline Cooling Time Before Ejection & $50 \mathrm{sec}$ \\
\hline Mould Temperature Prior to Injection & $40{ }^{0} \mathrm{C}, 50{ }^{0} \mathrm{C}, 60{ }^{0} \mathrm{C}$ \\
\hline Number of Shots & $20,40,60,80$ \\
\hline
\end{tabular}

Table 1 - Injection moulding parameters

A very low injection speed was used to completely fill all six impressions. This was important to guarantee that the specimens were subject to the same thermal conditions. All parts were injected using the same mould and ejection was performed manually. The procedure of cooling the mould between consecutive shots was used, adopting the mould temperatures prior to injection shown in Table 1 to obtain different thermal cycles.

\section{$\underline{\text { Tensile Test }}$}

All the specimens used in this experiment were built on an SLA7000 machine in SL7560 resin and post cured in a UV oven for 1 hour. Subsequently, all the specimens were measured using vernier callipers and stored at $20^{\circ} \mathrm{C}$ with no exposure to light. Specimens were only removed from controlled storage when they were submitted to injection moulding. After the injection moulding process, the specimens were returned to controlled storage. When all moulding experiments had been completed 
the specimens were submitted to tensile tests using a Zwick - Material Test Machine (TC-FR030TH.A1K) connected to a computer. This process of storage ensured that any effects of environment and time would be equal for all samples. One set of specimens was subject to no moulding; these were used as a reference to observe any changes caused by moulding.

In accordance with BS EN ISO 527-2: 1996, five parts were submitted to tensile test for each experimental moulding condition evaluated (number of shots and reference temperature). The following procedure was used to determine the mechanical properties for each set of specimens:

1. The dimensions of the specimens (width and thickness) were measured using digital callipers connected to the computer. For each measurement, three readings were carried out and the average value was recorded automatically by the computer program;

2. The specimen was positioned in the tensile test apparatus and submitted to tensile loading. After the specimen had been broken, the values of the mechanical properties measured were recorded;

3. The procedure was repeated for each specimen and the average values of the measurements were calculated.

After the tensile test, the results were organized and presented graphically as shown in the next section.

\section{Results and Discussion}

\section{THERMAL CyCLES DURING MOULDING}

Figure 3 shows the thermal cycles when using the three different reference temperatures prior to injection $\left(40^{\circ} \mathrm{C}, 50^{\circ} \mathrm{C}\right.$ and $\left.60^{\circ} \mathrm{C}\right)$. The maximum temperatures measured by the thermocouple during the moulding cycles were $76^{\circ} \mathrm{C}\left(40^{\circ} \mathrm{C}\right.$ reference temperature $), \quad 82^{\circ} \mathrm{C} \quad\left(50^{\circ} \mathrm{C}\right.$ reference temperature $)$ and $88^{\circ} \mathrm{C}\left(60^{\circ} \mathrm{C}\right.$ reference temperature). 


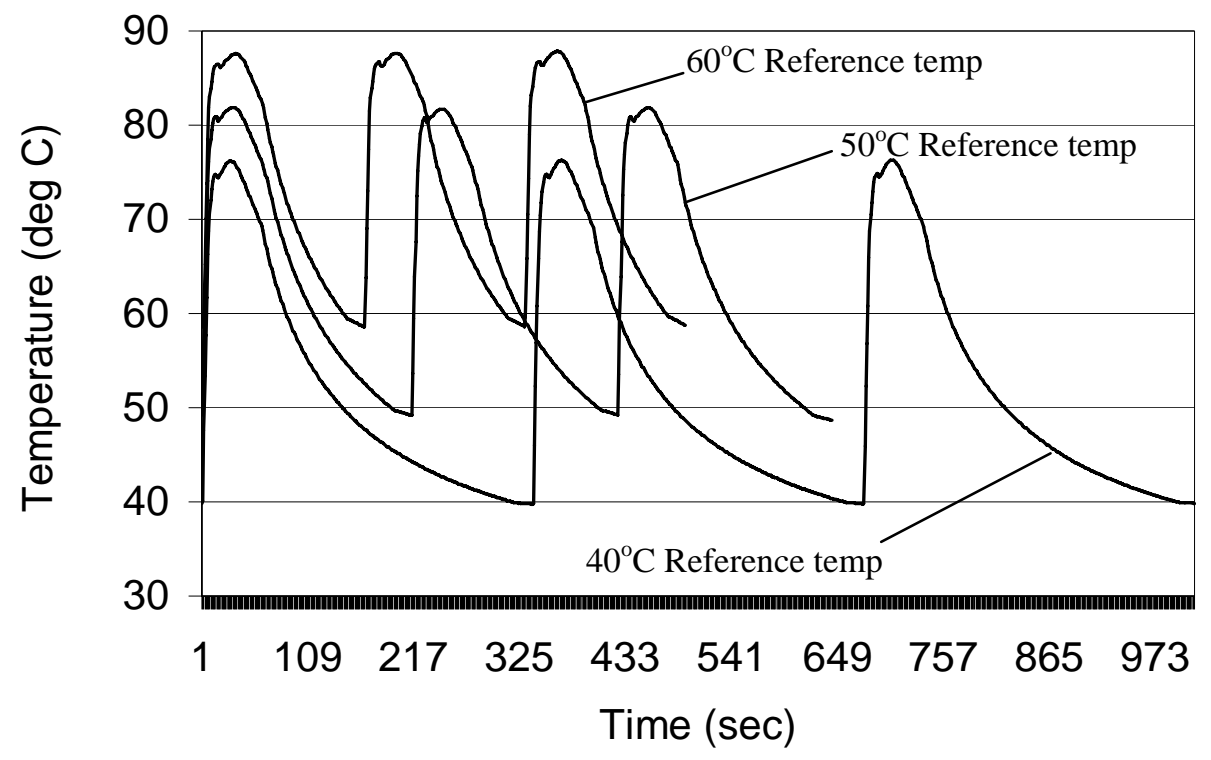

Figure 3 - Thermal cycles using different reference temperatures prior to injection

\section{TENSILE TESTS ON SPECIMENS}

A typical set of stress - strain graphs for a set of five specimens is shown in Figure 4. The tensile tests showed that the failure occurred by tensile loading with UTS being reached after significant plastic deformation. The results obtained for UTS and Young's Modulus are described below.

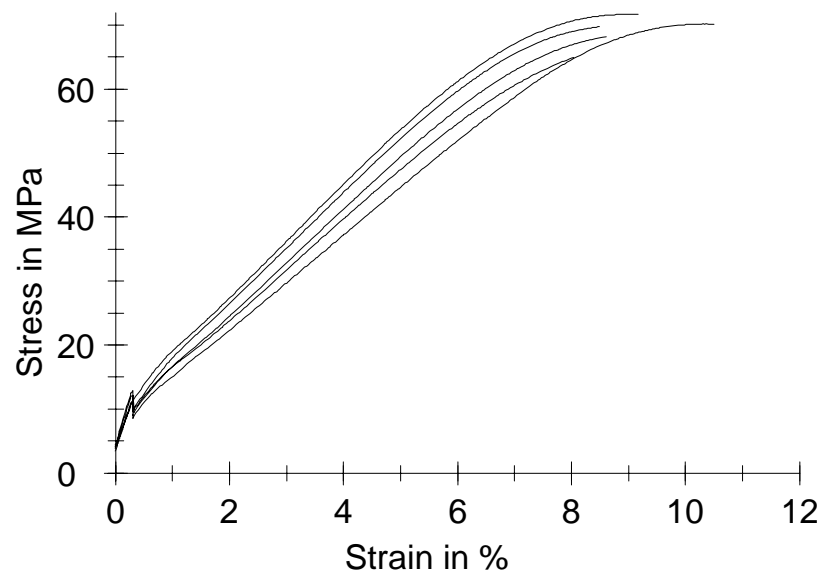

Figure 4 - Stress - Strain diagram for a set of specimens

\section{$\underline{\mathrm{UTS}}$}

Figure 5 shows the UTS as a function of the number of parts injected, for each reference temperature. The reference value of 70.5 MPa was obtained by evaluating the mechanical properties of the specimens that had not been submitted to injection 
moulding thermal cycles. This value was used as reference to evaluate the changes that occurred to the mechanical properties of the specimens. The results indicate that the UTS of the resin was slightly lower after being subjected to injection moulding cycles, however the effect was minimal. The difference between the lowest mean UTS (68.3 MPa) and the reference UTS (70.49 MPa) was approximately 3\%. Another important aspect is the lack of a trend in the graphs, subjecting resin to higher temperatures and more shots did not appear to either increase or decrease the UTS. These results suggest that the UTS may be slightly reduced by injection moulding but that continued moulding and the use of reference temperatures up to $60^{\circ} \mathrm{C}$ have no discernable further effect on the UTS.

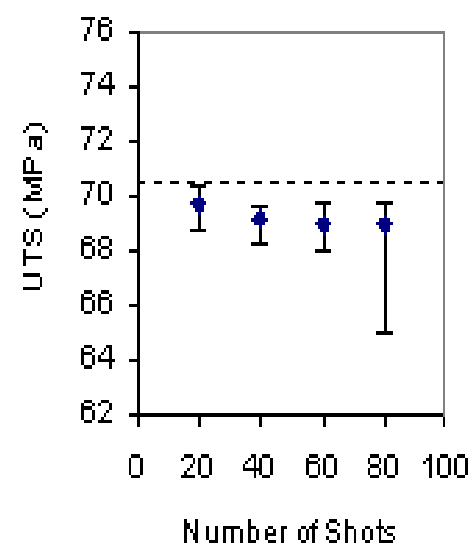

$40{ }^{0} \mathrm{C}$

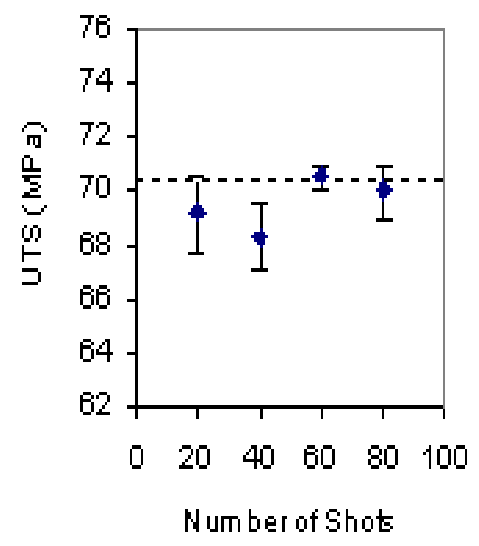

$50{ }^{0} \mathrm{C}$

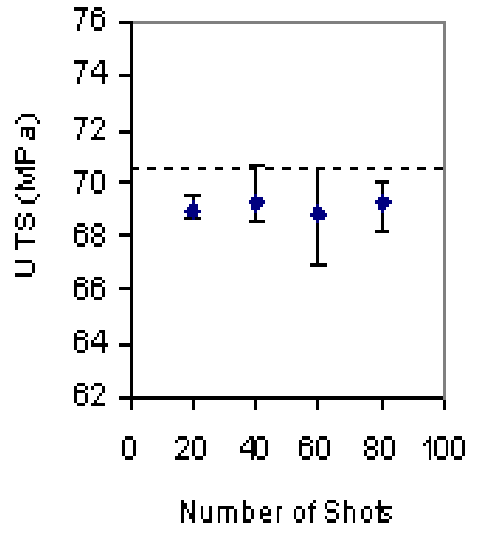

$60{ }^{0} \mathrm{C}$

Figure 5 - Ultimate Tensile Stress

\section{$\underline{\text { Young's Modulus }}$}

Figure 6 shows that the results of Young's Modulus measurements showed similar behaviour to those observed for UTS. Again, the use of this SL resin for injection moulding appeared to reduce the stiffness of the specimens, however no trend was observed in the measured values as a function of either temperature or number of injected parts. A maximum reduction in stiffness of up to $8 \%$ from the reference value $(\mathrm{E}=2,887 \mathrm{MPa})$ was observed, which was greater than that for UTS in percentage terms. 


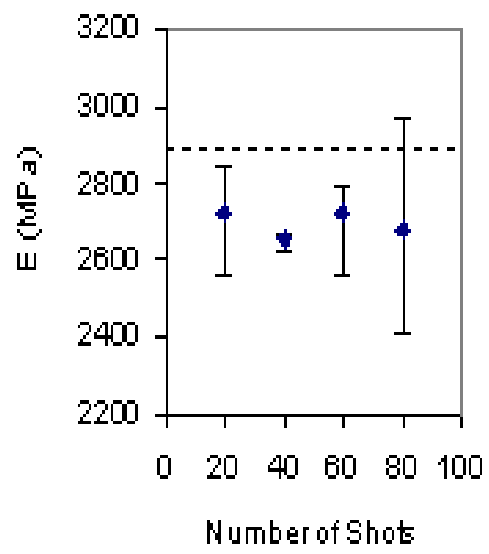

$40{ }^{\circ} \mathrm{C}$

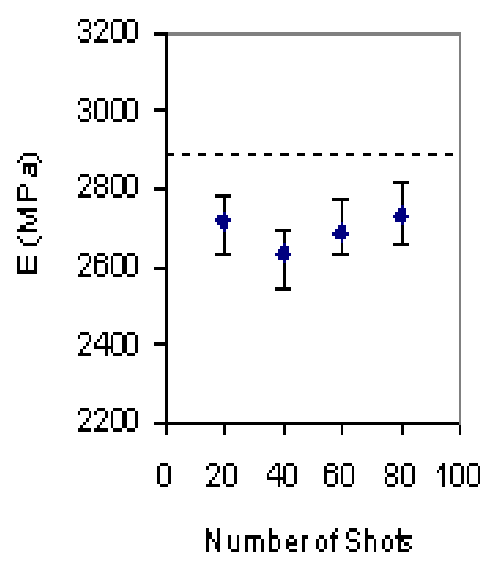

$50{ }^{\circ} \mathrm{C}$

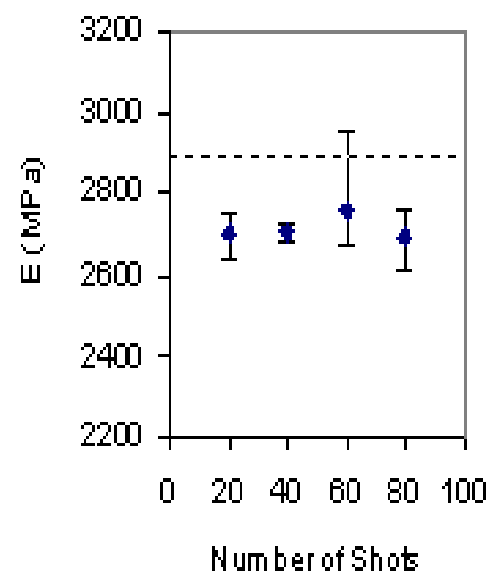

$60{ }^{\circ} \mathrm{C}$

Figure 6 - Young's Modulus

\section{Conclusions}

The injection moulding parameters used in this work were similar to those usually used for SL moulds. This kind of tool is generally used to manufacture a limited number of parts, because the SL moulds usually fail prematurely and because long cycle times are required. The changes in mechanical properties of the resin were evaluated, gradually increasing the thermal loading by changing the reference temperature prior to moulding and the number of shots moulded. The choice of the number of cycles to be applied and the reference temperatures were based on typical moulding conditions for these tools.

The experiments were developed to evaluate whether the changes that occur in the mechanical properties of the resin, during the injection moulding process, could cause the premature failure of the SL mould. The results showed minimal changes to UTS and Young's Modulus after injection moulding and these changes were not large enough to result in tool failure. The results showed that injection moulding, using the resin and parameters chosen for this work, caused less change in the mechanical properties of the resin than the usual post-cure thermal treatments. This suggests that mould breakage is more likely to occur as a result of high temperatures incurred during moulding rather than by any detrimental changes to mechanical properties over 
time. Consequently, by minimising the temperatures encountered by the mould (by allowing the tool to cool sufficiently between shots and, where possible using a short time prior to ejection) tools made from SL7560 resin should be capable of moulding large quantities of mouldings. Techniques such as the use of an air line to cool tools prior to moulding could help to achieve larger yields from SL tools. The use of thermocouples to identify suitable temperatures prior to moulding may be eliminated by using numerical methods to determine the time necessary to cool down the mould between the injection cycles.

\section{References}

CEDORGE, Thomas; LeBAUT, Yann LE; Palmer, ANNE; COLTON, Jonathan. “Design Rules for Stereolithography Injection Molding Inserts”. Proceedings of $\mathbf{8}^{\text {th }}$ European Conference on Rapid Prototyping and Manufacturing. Nottingham, UK. pp. 193-209. July, 1999;

COLTON, Jonathan; BLAIR, Bryan. "Experimental study of pos-build cure of stereolithography polymers for injection Molds”. Rapid Prototyping Journal, vol. 5 nº 2. pp. 72-81, 1999;

CONNELLY, R.; PARUNAK, G., "Microfluidics Applications Using High resolution Stereolithography”. Proceedings from the SME Conference on Rapid Prototpying and Manufacture. Cincinnati, USA, April 30, 2002;

HOPKINSON, Neil; DICKENS, Phil; HARRIS, Russ. "Layer thickness selection for stereolithography injection mould tooling”. Proceedings of $\mathbf{8}^{\text {th }}$ European Conference on Rapid Prototyping and Manufacturing. Nottingham, UK, pp. 7993. July, 1999;

JACOBS, P. F. "Rapid Prototyping \& manufacturing: fundamentals of stereolithography”. Society of Manufacturing Engineers Michigan, USA. 1992;

JACOBS, P. F. "Recent advances in rapid tooling from stereolithography”, White Paper, 3D Systems Inc. Valencia, California, USA. 1997; 
McLAUGHLIN, R. M. Jr. "Structural analysis and design of ACES stereolithography inserts for rapid tooling of prototype injection molds”, Master Thesis, Institute of Plastics Innovation, University of Massachussetts at Lowel, USA. 1996;

RAHMATI, Sadegh; DICKENS, Philip. "Stereolithography for injection mould tooling”. Rapid Prototyping Journal, vol. 3 n 2. pp. 53-60, 1997;

SALMORIA, G. V.; AHRENS, C. H.; FREDEL, M.; PIRES, A. T. N. "Fractography and micro-structural analysis of parts built by stereolithography”. Congresso em Ciência de Materiais do Mercosul, Joinvile - Brazil, sept/2002 (in Brazilian Portuguese);

WOHLERS, T., 2002. "Rapid Prototyping and Tooling State of the Industry - 2000 Worldwide Progress Report”, Wohlers Associates, Inc. Colorado, USA, 2001. 